PROFESSOR ROSS J. BALDESSARINI (Orcid ID : 0000-0001-9718-8211)

Article type : Letter to the Editor

\title{
Steroids and antidepressant response
}

To the Editor

Acta Psychiatrica Scandinavica

\section{Dear Sir:}

The recent meta-analytic review of trials involving anti-inflammatory agents to treat or to supplement treatment of patients with major depressive disorder (MDD) or depressive symptoms by Köhler-Forsberg and colleagues [1] includes data derived from 36 controlled trials. Treatments included glucocorticoids as well as cytokine inhibitors, minocycline, nonsteroidal anti-inflammatory drugs (NSAIDs), pioglitazone, and statins. There were 14 randomized, controlled trials involving addition of one of these agents versus placebo to standard antidepressants to treat acute episodes of MDD in 597 subjects. The resulting data analyzed by random-effects meta-analysis yielded a highly significant standardized mean drug-placebo difference (SMD) of -0.64 (95\% CI: -0.88 to $-0.40 ; z=5.17, p<0.00001)$ in which $9 / 14$ trials $(64.3 \%)$ individually yielded statistically significant differences, with moderate heterogeneity $\left(I^{2}=51 \%\right)$. Even though the numbers of trials of each class of experimental agents and their testing as monotherapies were quite limited and 5/14 trials (35.7\%) yielded nonsignificant drug-placebo differences, these findings overall indicate a noteworthy beneficial effect of adding an anti-inflammatory agent to standard antidepressant treatment.

Potentially relevant to this work are efforts in the 1980 s to evaluate the ability of the dexamethasone suppression test (DST) to predict responsiveness to treatment of MDD subjects with various antidepressants. Since nonsuppression of cortisol output by dexamethasone indicates the presence of elevated circulating corticosteroid concentrations, one might expect to find superior treatment responses among cortisol-nonsuppressors (DST-

This article has been accepted for publication and undergone full peer review but has not been through the copyediting, typesetting, pagination and proofreading process, which may lead to differences between this version and the Version of Record. Please cite this article as doi: 10.1111/acps.13056

This article is protected by copyright. All rights reserved. 
positive), based on the proposal that various anti-inflammatory agents, including glucocorticosteroids, might enhance responses to antidepressants [1]. The extensive body of research on the DST, though heterogeneous and including some findings of an association of cortisol-nonsuppression and favorable response to some antidepressants, led to the overall conclusion that initial DST-status had little predictive association with antidepressant response [2-5]. Although the circumstances of the preceding groups of studies are dissimilar, the very limited ability of DST to predict antidepressant response in MDD patients seems inconsistent with the hypothesis that anti-inflammatory agents as a class may contribute beneficial effects to the treatment of MDD, including when added to standard antidepressant drugs.

\section{Ross J. Baldessarini, MD}

Department of Psychiatry

Harvard Medical School

Mailman Research Center, McLean Hospital

Boston, Massachusetts, USA 02478

Email: rbaldessarini@mclean.harvard.edu

\section{Gustavo H. Vázquez, MD, PhD}

Department of Psychiatry

Queen's University School of Medicine

Kingston, Ontario, Canada

\section{References}

1. Köhler-Forsberg O, Lydholm CN, Hjorthøj C, Nordentoft M, Mors O, Benros ME. Efficacy of anti-inflammatory treatment on major depressive disorder or depressive symptoms: meta-analysis of clinical trials. Acta Psychiatr Scand 2019; 139:404-419.

2. Arana GW, Baldessarini RJ, Ornsteen M. The dexamethasone suppression test for diagnosis and prognosis in psychiatry: commentary and review. Arch Gen Psychiatry 1985; 42:1193-1204.

3. Gitlin MJ, Gerner RH. The dexamethasone suppression test (DST) and response to somatic treatment: a review. J Clin Psychiatry 1986; 47:16-21.

4. American Psychiatric Association Task Force on Laboratory Tests in Psychiatry. The dexamethasone suppression test: an overview of its current status in psychiatry. Am J Psychiatry 1987; 144:1253-1262.

5. Ribeiro SC, Tandon R, Grunhaus L, Greden JF. The DST as a predictor of outcome in depression: a meta-analysis. Am J Psychiatry 1993; 150:1618-1629.

This article is protected by copyright. All rights reserved. 